Página inicial: 58 - Página Final: 74

Tipo de artículo: Investigación.

\title{
Construir Artistas para la Vida. Experiencias pedagógicas desde la organización popular comunitaria. i
}

\section{Forming Artists for Life. Pedagogical Experience Based on the Community Popular Organization.}

\author{
Por: Mónica Rojas ${ }^{1}$ y John Jader Agudelo ${ }^{2}$
}

Recibido: Junio de 2016 Revisado: noviembre de 2016 Aceptado: diciembre de 2016

\section{Resumen.}

En Medellín, varias experiencias organizativas de base, le han apostado a la construcción de proyectos que articulen la cultura desde lo educativo y el arte logrando otras relaciones de afecto y efecto en territorios de alta complejidad social; Es así que, la presencia y proyección de estos colectivos se ha convertido en un "creer en crear, desde lo local, desde lo propio". Ese es el caso de la experiencia organizativa del Colectivo "Nuestra Gente". Un proceso que tanto en su accionar organizativo como en su devenir histórico- político aparece trenzado con la herencia latinoamericana en los barrios de Medellín.

Palabras clave. Formación popular comunitaria, experiencias pedagógicas urbanas, formación cultural, participación política experiencia formativa.

\begin{abstract}
.
In Medellin, several fundamental organizational experiences, have been interested in the construction of projects, which can articulate culture from the educational and cultural points of view. This has helped to establish other relations of affect and effect in high-social complexity territories and high-armed violence. This, without necessarily taking into account Institutionality, which for this case is the municipal administration. That is how that the presence and the projection of these groups have become in "believing in creating, from the local, from what is proper." That is the case of organizational experience of the "Our People" group.
\end{abstract}

Key words. Community popular formation, urban pedagogical experiences, Cultural Formation, Formative Experience, Culture, and Political Participation.

\footnotetext{
${ }^{1}$ Licenciada en Educación básica con énfasis artístico cultural: artes representativas, Estudiante de Maestría en psicología cognitiva y aprendizaje en Flacso, Argentina. Integrante de la Corporación Cultural Nuestra Gente: desde el año 2002 como participante de los procesos de formación y desde 2007 como actriz, docente y coordinadora de procesos de formación artística. Contacto: moniroja@gmail.com

2 Licenciado en Lenguas de la Universidad de Antioquia, Magister en Educación de la Universidad de Massachusetts, Doctor en Estudios Culturales Latinoamericanos de la Universidad Andina Simón Bolívar, integrante del grupo de investigación Diverser y Docente de la facultad de Educación de la Universidad de Antioquia. Medellín (Colombia).Contacto: johnjader@gmail.com
} 


\section{Introducción.}

La experiencia latinoamericana atraviesa celularmente los barrios de Medellín desde una pluralidad de vivencias populares y comunitarias.

Con el fin de extender los lazos contextuales que envuelven estas prácticas vitales arraigadas en sus territorios, se hace pertinente evocar algunos de esos hilos que, desde la historia oficial, aparecen frecuentemente negados o fragmentados en trozos sin sentido. En ese abanico de historias organizativas comunitarias encontramos a Nuestra Gente -en adelante NG — situada en Santa Cruz, en la Comuna 2 de Medellín. Este colectivo ha sido permeado por diversas raíces desde la perspectiva liberadora latinoamericana: la vida de Camilo Torres, la Teología de la Liberación, la Educación Popular, la Organización Popular Comunitaria, las Comunidades Eclesiales de Base, entre muchas otras que hablan de la siembra de utopías, pero también de la forma en la cual las políticas de la diferencia colonial moderna son estructuralmente reflejadas en fenómenos como el poblamiento urbano y la representación que se construye desde la modernidad sobre las poblaciones de los barrios populares.

En los años 60 la migración campesina a las ciudades, tanto en Colombia como en el resto de Latinoamérica, se convirtió en un eje fundamental para el nacimiento del movimiento popular urbano. Los sujetos que se adscribirían a este movimiento fueron situados dentro de una clase popular urbana por parte de la teoría sociológica, pero su organización, más allá de la teorización, desde su accionar político reconfiguró las relaciones sociales, culturales y políticas dentro de muchas urbes colombianas.

En este mismo sentido, para entender el territorio de siembra de esta Nuestra Gente debemos ubicarnos en el contexto local urbano que la ve nacer como organización comunitaria durante los años 80, desde el cual los territorios urbanos de Medellín, como la Comuna 2 (Zona nororiental), fueron atravesados por dos fenómenos particulares, pero de sentidos opuestos.

Por un lado, la ciudad de Medellín experimentaba una profunda crisis social alimentada por el fenómeno del narcotráfico, y en los barrios populares se genera una articulación entre delincuencia juvenil desde bandas y combos al emporio del narcotráfico, que termina vehiculizando estos grupos (Salazar, 1993). Esta situación construyó un reconocimiento desde el estigma sobre los habitantes de la zona nororiental y la ciudad, dejó en la memoria nacional el virus del narcotráfico que infectó desde sus prácticas y lógicas el tejido sociocultural, y llegó a ingresar en los altos de la política colombiana. Por el otro surgen las milicias urbanas como estrategia de fortalecimiento de la presencia guerrillera en las ciudades.

Para el año 1995 la zona nororiental sumaba 65 bandas de un total de 164 en toda la ciudad (Plan de desarrollo Local Comuna 2). La historia de los sectores populares en cuanto a sus derechos básicos como tenencia de la tierra y servicios públicos, estuvo vinculada a la "ilegalidad"; además estos lugares fueron tomados como los de mayor número de muertes en una ciudad catalogada dentro de las más violentas del mundo en las décadas de los 80 y los 90. 
(Insuasty Rodriguez, Bastidas , Carrion, \& Balbin Alvarez, 2010); (Insuasty Rodriguez \& Villa Holguin, 2014)

El lado opuesto a este panorama, es el surgimiento de una ola organizativa y comunitaria que en la década anterior se venía gestando desde los sectores populares como consecuencia del fortalecimiento de los actores sociales y su lucha reivindicativa por derechos sociales, culturales y económicos.

Los jóvenes que habrían de juntarse para materializar el sueño de Nuestra Gente crecieron bajo el legado de la Teología de la Liberación y como parte de grupos juveniles recibieron el apoyo de los religiosos y sacerdotes que llegaron a esta comuna como Horacio García, Vicente Mejía, Federico Carrasquilla, Hernán Muñoz. Desde allí hubo acercamientos con comunidades eclesiales de base, que iniciaron su trabajo con la enseñanza del catecismo y se diversificaron en el encuentro comunitario con religiosos de distintos orígenes.

Estos jóvenes empezaron a identificar diferentes líneas de pensamiento al interior de la misma Iglesia. Conocieron dos instituciones: la que entregaba el dinero recolectado al vaticano y la de iglesia popular que dirigía su trabajo hacia los pobres: "un día voy a la Iglesia de la Divina Providencia y me encuentro con el Padre Federico Carrasquilla, tiene una alcancía que es comunitaria, la gente viene y el padre le dice: "mija tome las monedas que necesita, eso es para todos, pero piense que detrás de usted vienen otros" (Entrevista a Jorge Blandón, Director y Co-Fundador de NG, Marzo 5 de 2013).

Estos jóvenes tuvieron encuentros con sacerdotes, las Terciarias Capuchinas y una misionera española, y comenzaron a hacerse preguntas por "el hombre viejo y el hombre nuevo", a recibir la música latinoamericana como mensajera de la realidad cercana desde Nicaragua y el Salvador, la canción social y el rock en español se volvieron parte de la misa. Aunque la fe movilizaba los jóvenes del grupo juvenil, es decir, la praxis era inherente a su juventud, esto no bastó o quizás fue la razón para que las diferencias con el párroco terminaran sacando su acción y juventud por fuera de las paredes de la iglesia, pero llevándolos hacia la ruta de lo comunitario.

El legado latinoamericano de la Teología de la Liberación, el pensamiento marxista y freiriano, la educación popular, así como el teatro del oprimido de Boal y el comunitario, sirven de puente epistémico para construir nuevas formas de relación con el territorio (Zibechi, 2014). Aquí el pensamiento latinoamericano no llega solo desde el texto escrito o la acción fundada en Marx, y se entiende como pensamiento cantado, con arte y alegría. El teatro y la música cobran sentido en un contexto de conflicto y profundas asimetrías sociales.

Gloria Naranjo, expresa frente a este tipo de propuestas en la nororiental:

"En las décadas del 70 y el 80 emergen organizaciones cívico-comunitarias. Buscaban ante todo métodos distintos de trabajo con las comunidades a través de propuestas educativas y de tipo cultural y recreativo. Se formaron grupos culturales y artísticos, bibliotecas populares de gran impacto sobre 
los pobladores que agenciaron un enfoque y una práctica de la cultura popular muy ligada al folclor y a ciertas tradiciones populares" $(1991,48)$

Estos diálogos estuvieron alimentados por la relación con una exreligiosa y su compañero quienes desde el compromiso profundo con la trasformación y la cercanía a la Teología de la Liberación enriquecieron el pensamiento político y la utopía de estos jóvenes.

¿Qué llevó a NG a construir una propuesta pedagógico-artística para este territorio? El momento histórico de una ciudad con una descomposición social en crecimiento, y al tiempo, con la persistencia de relatos de esperanza conectados con la transformación y movilización de las inquietudes de los jóvenes en torno a la vida, el arte y el barrio, que decidieron conscientemente asumir un proyecto propio. En 1987 mientras varios jóvenes optaban por el combo del barrio, estos 36 jóvenes optaron por alimentar la vida. De esta forma, basados en la autogestión alquilaron una casita en el barrio, juntaron 50 libros y crearon una biblioteca popular y una casa para la cultura. Desde allí se apoyaban las tareas de los niños, se sacaba un teatrino que a través de títeres y en ocasiones música de guitarra recordaba la alegría de ser niño en la complejidad de este contexto. No es casual que el primer festival de Nuestra Gente fuera denominado el "Festival de la Cultura y la Alegría".

\section{La emergencia de una organización comunitaria barrial: crecimiento de la semilla.}

Los contrastes y tensiones en el territorio son una realidad constante en Medellín, palpable desde la misma génesis del proyecto organizativo de Nuestra Gente. Este panorama hace parte de las complejidades socioculturales en medio de las que forja la experiencia organizativa de Nuestra Gente, considerado uno de los procesos históricos de base en Medellín por su incidencia y aportes.

De acuerdo a Naranjo (1992), las primeras organizaciones de la Comuna 2 de Medellín, surgen en la década del 70. Hijas del movimiento cultural de estos barrios buscaban una construcción reivindicativa que superara la lucha por el acceso a servicios públicos. Entretejieron en su constitución lo organizativo con teatro, música, danza y bibliotecas populares, promoviendo así una práctica de la cultura popular. En ese sentido, ya a finales de los 80 se percibe una dirección política y culturalmente intencionada que contribuyó a romper el estigma de lo popular en la ciudad en esta década.

De igual manera, en este tiempo la zona nororiental se caracterizaba por la constitución de organizaciones de base comunitaria. Muchas de ellas se presentan autónomas frente al Estado y los grupos de izquierda. Se resalta la capacidad de control político de estas organizaciones frente al interés y vehiculización que los partidos políticos o grupos de izquierda procuraban llevar a cabo (Bernal, 1992).

En este artículo se define organización comunitaria como un encuentro colectivo barrial organizado bajo propósitos de supervivencia y transformación que obedecen a las condiciones políticas, socio-culturales y del territorio (Hidalgo, 2004). Esta forma de nombrarse es 
autoreferenciada y surge desde el proceso "Redes comunitarias locales entre la supervivencia y la emancipación", un proceso articulado que surge desde el red-tejer de las organizaciones comunitarias.

Es esta línea al hablar de la noción de lo popular desde los referentes propios de las organizaciones en Medellín, el educador popular Edison Villa afirma que "no se refiere al significado de carencias, ni a lo masivo, sino que tiene que ver con los procesos organizativos que se van configurando acorde a las condiciones socio-culturales e históricas de las comunidades" (Villa 2010, p.120). Esta conceptualización de organización comunitaria puede encontrarse una configuración epistémica que surge desde la experiencia construida colectivamente en el mundo organizativo, es decir, está en consonancia con la postura crítica del pensamiento latinoamericano que defiende una perspectiva de praxis sustentada en la dialéctica entre la experiencia de las comunidades en sus territorios concretos y la reflexión sobre lo que construye la vida en dichos escenarios.

Aquí se acoge una mirada situada y asumida desde la práctica de las organizaciones comunitarias, y en consecuencia un acercamiento a los hilos de sentidos que mueven a una organización popular comunitaria como NG a construir a lo largo de casi tres décadas un proyecto de vida anclado a lo comunitario como base para desarrollar procesos artísticopedagógicos.

\section{Metodología.}

Este proceso de investigación se sitúa en el horizonte de la teoría social crítica con un enfoque interpretativo - etnográfico. La teoría social crítica como parte de un paradigma cualitativo, reconoce a los actores de las distintas comunidades de saberes como interlocutores y dadores de sentido colectivo.

Igualmente, Este apartado del estudio da cuenta de análisis de documentos, entrevistas y registros de observaciones participantes, para considerar los procesos formativos de Nuestra Gente desde la visión política y cultural de su apuesta artístico- pedagógico de base comunitaria.

Este colectivo ha sido permeado por diversas raíces desde la perspectiva liberadora latinoamericana lo cual ha servido de puente epistémico y político para construir nuevas formas de relación con el territorio y la comunidad. La configuración de una apuesta artístico pedagógica bajo los sentidos de "Construir artistas para la vida", direcciona los procesos de formación desde los cuales el teatro comunitario se convierte en protagonista de un accionar político-pedagógico.

Esta sintonía con el legado latinoamericano lleva a Nuestra Gente, a participar desde un saber red-tejido, con el proyecto latinoamericano de Cultura Viva Comunitaria permitiéndole ampliar su incidencia a lugares más allá del ámbito local y nacional. 


\section{Resultados.}

\section{Construir Artistas para la Vida.}

La experiencia pedagógica de una organización popular comunitaria como NG, está anclada bajo la premisa fundacional "hay que contradecir la muerte", y de esta manera los fundadores de NG se acercan a otros jóvenes, para desde ahí potenciar el cambio social. Mediante el arte y el teatro estos fundadores llegan a diferentes barrios de la zona nororiental y acompañan grupos de jóvenes para hacer teatro desde sus propios lenguajes, a crear desde la vida y a alimentar la esperanza. NG fundamenta su apuesta pedagógica en tres ejes; la formación de sujetos éticos, sociales y políticos, con un enfoque que busca la recuperación del tejido social desde la base, la comunidad.

La ruta creativa y pedagógica de NG tiene como lema, "Construir artistas para la vida", desde allí se direcciona los procesos de formación y se concibe posible que muchos de los participantes de sus procesos no opten por ser artistas profesionales, pero desde su construcción artísticopedagógica se prioriza que sean artistas de sus vidas. Esta ruta busca procesos enraizados en el territorio y la realidad, que respondan a las necesidades específicas de los sujetos que lo habitan. Esto es posible gracias a una construcción que ha sido tejida por facilitadores, participantes y gestores, los cuales pertenecen a un colectivo que actúa en pro de los procesos pedagógicos de la corporación. Este espacio permite una relación dialógica constante entre los actores que lo conforman, lo cual fortalece tanto la búsqueda de una construcción comunitaria como el planteamiento de nuevos proyectos desde la Casa Amarilla (nombre que se le asigna a la sede de Nuestra Gente, por el color de la fachada externa que tiene esta casa)

La formación apuesta a que los sujetos que vivan el proceso fortalezcan sus habilidades sociales -comunitarias, que sean sujetos solidarios y alegres, con capacidad de toma de decisión desde el pensamiento colectivo (Zemelman Merino, 2015), que sean partícipes de la construcción de nuevos entornos de vida y transformen realidades desde la familia y el barrio. Este proceso formativo da paso a la constitución de subjetividades en tres líneas: una subjetividad política caracterizada por su participación activa en procesos de trasformación, una subjetividad estética caracterizada por su creatividad y sensibilidad, y una subjetividad ética caracterizada por la solidaridad y el afecto.

Estas subjetividades dan cuenta de tres principios de formación que concibe NG: la solidaridad, el afecto y el respeto que transversalizan la propuesta desde lo artístico, lo humano y lo organizativo.

La solidaridad es una expresión del deseo de desarrollar un pensamiento colectivo, lo cual se manifiesta desde la integración al grupo. Se concibe un sujeto vinculado a lo social/colectivo, es decir, un joven no ingresa a un taller, ingresa a un grupo. Las temáticas a tratar en el grupo son problematizaciones que se ven como afectaciones a un colectivo y buscan generar una reflexión colectiva, "se aprende mediante la acción colectiva. Esta acción debe ser consecuente, transformadora e incluyente; para la Corporación Cultural Nuestra Gente es el arte, como acción 
dadora de vida" (Rojas 2011, p.102). Este principio es también expresado en la relación con la comunidad barrial al exterior desde el trueque que busca generar una relación de reciprocidad entre actor y espectador-comunidad.

El afecto es asumido como una conexión vital con el otro, como una fuerza movilizadora. En ese sentido las relaciones no se establecen desde la disciplina en los procesos de formación, sino que se apela a la voluntad de cada sujeto donde la obligación se transforma en capacidad volitiva, partiendo de la pasión y el gusto.

Desde la construcción de NG, esta es una ruta de formación para aprender y aprehender, considerando que aprender es un proceso que se da en la mente y puede ser significativo o no para el sujeto, pero cuando se aprehende se pasa por el cuerpo, se generan aprendizajes significativos que parten de la voluntad y la motivación, los aprendizajes parten del sujeto, de su interacción con el medio que habita y las relaciones que se generan en su entorno, la escuela pone las competencias en el centro y su pedagogía se enfoca en lo cuantitativo, contrario a esto un aporte de Nuestra Gente está en dirección de una pedagogía desde lo cualitativo, que habla del aprendizaje y el diálogo en movimiento, es decir, el trabajo que se hace desde la formación en procesos como la creación colectiva, donde el montaje de una obra demanda una acción sentipensante, movilizar el pensamiento y el cuerpo, pensar el territorio desde lo social, cultural y político.

Una de las rutas metodológicas en las que las prácticas pedagógicas están enraizadas es la de "aprender-haciendo", “aprender-jugando" y "aprender-creando". Esta vía permite establecer una relación con un conocimiento que involucra todo el cuerpo.

En el aprender haciendo a través de un proceso de aprehensión que involucra al cuerpo articulado a lo vivencial, se da una praxis desde el contexto inmediato, por esto los talleres involucran ejercicios prácticos, con una construcción constante de aprendizajes desde la reflexión colectiva. En los encuentros se hacen improvisaciones y representaciones de temáticas cotidianas, sobre los cuales el grupo reflexiona, los participantes exponen su punto de vista y desde la escena se propone estrategias que buscan solucionar o entender a lo ocurrido dentro de la problemática planteada.

En el aprender jugando, nuevamente el cuerpo es el lugar de partida del aprendizaje. Desde el juego se establece una relación lúdica con el contexto, que alimenta el gusto y la motivación por el aprender, rompiendo así con los cánones de la disciplina escolarizada, es decir, el juego permite procesos de socializaciones y relaciones desde un lugar no disciplinado. Para esto el grupo de facilitadores constantemente reelabora ejercicios técnicos de las artes a lenguajes lúdicos, de forma que el concepto sea interiorizado con el juego como ruta de aprehensión.

En el aprender creando se plantea que el hacer y el jugar tiene un propósito que pasa por la creación lo cual en términos pedagógicos representa la materialización de lo aprendido. Se aprende creando desde el hacer y el jugar, se trata de "Liberar el universo de cada ser, la creación permite esto y que se conjugue con los universos de los otros y que de allí surgen cosas nuevas"

\begin{tabular}{l|l|l|l|l|l|l}
\hline AGO.USB & Medellín - Colombia & Vol. 17 No. 1 & PP 1 - 323 & enero - junio & 2017 & ISSN: 1657 8031
\end{tabular} 
(Entrevista a Rojas, 2013). En breve el arte y en mayor medida en NG, el teatro, es el medio que libera la creación de cada sujeto sin perder el vínculo colectivo. Cada grupo crea puestas en escena que son presentadas periódicamente en distintos espacios, estas surgen de temáticas que se proponen desde lo grupal, en procesos orgánicos decididos por el grupo y el facilitador. El proceso inicia con una exploración colectiva de temáticas, surgida de las preocupaciones, inquietudes o intereses de los participantes. A partir de distintos ejercicios prácticos se investiga sobre un tema, cuya elección final es grupal y sobre la cual el facilitador busca: un texto narrativo, un texto dramático o una creación colectiva. El montaje se inicia a partir de improvisaciones individuales y grupales, de las cuales se selecciona el material que será parte de la puesta en escena, el facilitador hace las funciones del director de escena, que organiza y marca las acciones. El montaje se convierte en el terreno para la reflexión, investigación y análisis de la temática propuesta, además le permite al grupo tener un punto de vista que se verá reflejado en la obra final y se comparte con la comunidad.

Se aprende creando, trascendiendo la limitación e impulsado por la construcción autónoma de aprendizajes desde una perspectiva liberadora. En el sentido Freiriano involucra una pedagogía de la problematización donde las preguntas son construidas por el sujeto mismo, la base del aprendizaje es la experiencia propia que busca ser vinculada al colectivo y en consecuencia a la cotidianidad, es una metodología que permite que sea más importante los procesos de los sujetos y del grupo, que los resultados.

El teatro comunitario de NG devela un saber acumulado detrás de bambalinas que teje un saber artístico, un saber cantado, un saber pedagógico comunitario que refleja el accionar constante de procesos formativos y de creación no regulados por las mediaciones escolares a las que estamos acostumbrados. La ruta de creación colectiva que NG entrelaza con el teatro comunitario permite vincular la configuración de subjetividades desde su dimensión política al anclar los sentidos que allí se articulan tanto al territorio como al fortalecimiento de los hilos comunitarios.

Podemos ver esta relación dialéctica con el territorio desde una práctica que involucra la participación directa de la comunidad a través del Teatro Comunitario.

"El teatro comunitario se construye a través de la voz de las comunidades, para la puesta en escena de obras que se tejen desde lo intergeneracional, en una propuesta de dialogo permanente, donde hay una valoración por el otro que contribuye a la sostenibilidad del carácter vinculante y fraternal de la humanidad” (Quintero y Muriel 2014, p.22)

En el 2012 se celebraron los 25 años de trabajo comunitario de NG, esta conmemoración se dio a través del proceso de construcción de la obra $Y$ cuando llegamos éramos otros. Una puesta en escena multifacética en la calle donde la Casa Amarilla es a la vez actriz, escenografía y memoria viva de la obra. El propósito fue construir desde el teatro comunitario una obra que pueda devolverle al barrio esta memoria viva. Una puesta en escena en plena calle publica del barrio Santa Cruz que involucró 75 personas actuando entre padres de familia, abuelas, niños y niñas, jóvenes y adultos. Una historia que da cuenta de la migración campesina, los curas de la Teología 
de la Liberación, la vida alegre de "Copinol 2", el burdel que hoy se llama "la Casa Amarilla" y las dinámicas de vida de una comunidad que le dieron vida a un territorio

En esta construcción artístico-pedagógica característica de la identidad organizativa de NG, se materializa una práctica pedagógica que tiene como lugar de partida el diálogo con el territorio desde una escucha que atesora la memoria de sus habitantes y sus sitios de encuentro: tiendas, calles y burdeles. Permitiendo activar una memoria viva y situada que se sistematiza en un saber comunitario que nos habla de la cultura barrial.

Enunciamos algunos aspectos brevemente que se entretejen desde esta creación de teatro comunitario:

-La construcción de una obra comunitaria conlleva una diversidad de interacciones que resignifican los sentidos sobre un territorio y la posibilidad de reconstruir la memoria desde el cuerpo. El “espectáculo escénico” no es el propósito, más bien el valor del artista comunitario está medido por su relación con la calle, entendiéndola como la vida diaria de la comunidad barrial.

-El ofrecimiento de una obra comunitaria al barrio que involucra a sus habitantes contiene un sentido pedagógico sentipensante donde lo solidario y lo afectivo se hacen manifiesto, no solo en razón de la práctica artística compartida, sino que al contener la memoria viva; se honra la vida de quienes lucharon para que este territorio pudiese albergar la cultura barrial que le da identidad.

-El proceso creativo al interior de la obra facilita aprendizajes colectivos que articulan al niño o al joven, ya que encontramos madres e hijos o abuelas y nietos actuando juntos, es una construcción intergeneracional que alimenta el tejido social comunitario.

-Contar la historia desde sus propios habitantes es un ejercicio de conciencia histórica emancipadora que permite reescribir la historia propiciando un dialogo intergeneracional desde el cual los jóvenes y niños pueden reconocerse tejidos al territorio desde la memoria colectiva.

El territorio es el campo de práctica pedagógica de esta apuesta: la figura del pedagogo colectivo que usando como mediación la obra, ofrece el contexto de realidad y la pregunta sobre lo que se quiere transformar o aquello que no se alcanza a percibir como trasformación. Se da la acción pedagógica desde la creación pensada en profundidad y la pregunta que se presenta alimentada, más no terminada, por las percepciones y reflexiones que hicieron parte de la construcción de un montaje. Es decir, el pedagogo colectivo carga de intención comunitaria su propuesta antes de llevarla al escenario. En el escenario, la acción pedagógica finaliza con el teatro foro donde el espectador y el actor dialogan desde el suelo de la reflexión propuesta.

\section{Sentidos vitales de formación.}

En la historia organizativa de Nuestra Gente, su construcción comunitaria aparece vinculada a una propuesta que circula desde el crecimiento colectivo e individual en su interior hacia la 
creación de procesos y proyectos que buscan transformar las condiciones de los sectores populares de este territorio. En este sentido, dentro de los procesos de formación intencionados sistemáticamente desde Nuestra Gente se ubican tres momentos con temporalidades que van desde 1997 hasta el 2012. Cabe resaltar estos ciclos por su trascendencia y aportes tanto al interior del proceso como a la construcción de otra subjetividad desde su propuesta de formación centrada en lo comunitario barrial. Por tanto, es preciso referirse a estos tres ciclos y a la forma en la que dan cuenta de la reflexión político-pedagógica destacando aspectos importantes en cada ciclo dentro del proceso organizativo.

\section{MOVILIZACIÓN DE LA FORMACIÓN}

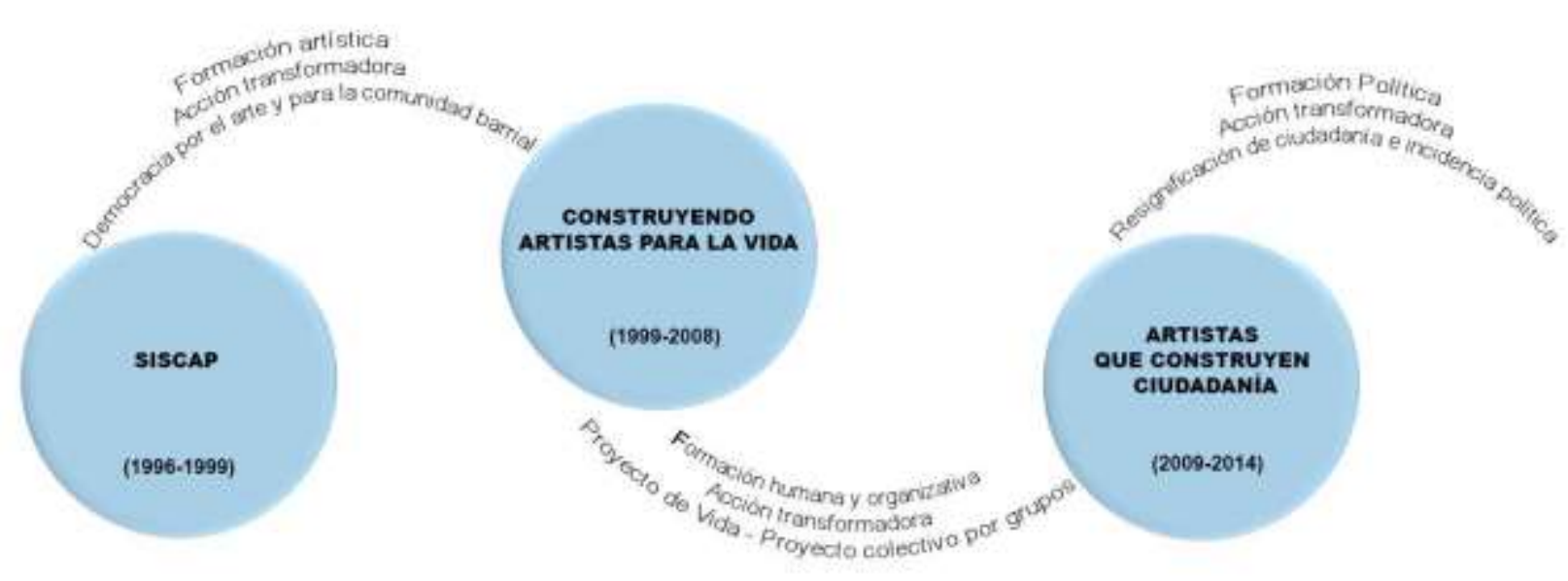

El Sistema de Capacitación y Asesoría a grupos juveniles de teatro -SISCAP es asumido como la semilla de los procesos formativos en NG. Este proceso de formación inició en 1996 y tiene una segunda fase en 1997, su objetivo fue el acompañamiento a grupos juveniles de teatro en distintas zonas de la ciudad, con una mirada centrada en la Formación Artística, en su desarrollo se delineó el horizonte también hacia la formación humana y organizacional.

En Construyendo artistas para la vida la pregunta por el sujeto y su proyecto de vida estaba influenciada desde la perspectiva de Max Neef y su desarrollo a escala humana. Este proyecto se realizó del año 1999 al 2005, en este ciclo se destacó una mayor claridad y énfasis en el tipo de subjetividades que se buscaba constituir desde los proyectos formativos. El trabajo desde la subjetividad a partir de los proyectos de vida se tornó altamente relevante ya que las condiciones socio-culturales de esta época eran complejas, abundaba la desesperanza. Esto sumado a las pocas posibilidades de acceder a la educación u otras alternativas de formación, lo cual ameritó que desde los proyectos de vida se impulsara lo vocacional junto a la utopía. Al final del proceso apareció desde los jóvenes la pregunta por la formación política y la incidencia desde ellos en procesos locales de desarrollo. 
Esta pregunta por lo político fue el surgimiento de la siguiente etapa "Artistas que construyen ciudadanía” y se realizó durante 2009 al 2012. En este se dio un cambio de enfoque, la intención viró hacia la exigibilidad de derechos humanos. La nominación de "Artistas que construyen ciudadanía" se originó en la misma preocupación de los jóvenes que formularon el proyecto a partir de su pregunta por otra ciudadanía que les permitiera incidir y participar en la toma de decisiones. Es decir, más que una complicidad a la narrativa de una ciudadanía simple o al derecho a ser parte de la ciudad, se trató de comunidades barriales en un ejercicio político donde los jóvenes desarrollarán la capacidad de toma de decisiones con interés colectivo y de incidencia sobre su comunidad (Montoya, Rojas, y Castañeda. 2012). También hubo una maduración desde la formación artística, humana y la organizacional, se reflexionó y se definieron los ciclos de formación de los grupos dentro de la corporación, lo cual se hizo a partir del símil con la metamorfosis de la mariposa.

\section{Una visión propia de los ciclos de formación: el ciclo de la mariposa.}

Uno de los aprendizajes más relevantes de "Artistas que construyen ciudadanía" fue comprender los ciclos formativos desde otra lógica diferente a los referentes del mundo académico, no como grados que se superan con una nota que mide el aprendizaje, o de lo contrario no se está aprendiendo. Desde NG el proceso es orgánico y vivencial, y los grupos los viven con sus ritmos, sin imponer estructuras o tiempos. La corporación alcanza una comprensión desde procesos de cohesión al interior de cada grupo, entendiendo el desarrollo particular de cada uno. El paso de un ciclo a otro lo determina su propio crecimiento y se hace basado en la metáfora de metamorfosis de la mariposa monarca. Este ciclo empieza por la crisálida, y continua con el nacimiento de la mariposa, la migración y la polinización (Rojas, 2011).

La escuela enseña por grados y niveles estandarizados desde un orden homogéneo donde todos aprenden lo mismo, a la misma edad, con la misma velocidad y desde la misma mirada. NG se reconoce en su ciclo que el aprendizaje es significativo desde la diferencia entre los sujetos, sus miradas y sus procesos de aprendizaje. Concibe que el grupo es esencial en este desarrollo ante la sobre determinación de la individuación en la escuela tradicional. El grupo no debe limitar, sino que busca potenciar sus habilidades, ayuda a crear identidad y sentido colectivo.

La articulación de este proceso desde referentes enraizados en la propia experiencia organizativa permitió la construcción de un nuevo entendimiento del ciclo formativo en su estructura como parte de una re-configuración de los sentidos de formación que le dan vida a la propuesta pedagógica. El proceso de reflexión sobre este ciclo logra un entendimiento de dinámicas de trasformación de los grupos, incluyendo la posibilidad de desaparición de un grupo como parte del ciclo mismo, lo que refleja que se valora más el camino que la llegada a una supuesta meta. 


\section{Red-tejer.}

Desde sus inicios NG ha tratado de buscar espacios de participación que permitan impactar la comunidad desde una construcción que vincula cultura y educación como ejes fundamentales del desarrollo local comunitario. Durante el periodo del proceso "Artistas que Construyen Ciudadanía”, NG venía realizando un esfuerzo por incidir en los espacios de participación política con el fin de articular su construcción colectiva con el desarrollo local de estas comunidades. Un ejemplo de esto es su protagonismo en las planeaciones locales como el Plan de Desarrollo Local (2007-2019) de la Comuna 2, en donde la versión de "Seguimiento y Evaluación" (2012) de este Plan, fue elaborada con Nuestra Gente y Convivamos -otra de las organizaciones históricas importantes de la zona Nororiental. Este Plan de Desarrollo asumido bajo el lema "Un mapa abierto a las propuestas de vida de la gente 2007-2019", plantea una visión para la Comuna 2 que da cuenta del tipo de perspectiva por la que han luchado estas organizaciones de base:

En el 2019 la Comuna 2 Santa Cruz se destacará por capacidad de gestión y autogestión para planear su territorio con base en el desarrollo integral a escala humana. Sobresaldrá la unidad comunitaria entre sus líderes, lideresas y organizaciones comunitarias, las cuales serán reconocidas por la promoción de la inclusión comunitaria en todo su territorio, con sus pobladores y en todas las dimensiones del desarrollo. (Plan de Desarrollo de Medellín 2012, p.10)

Desde su accionar político particular y en su red-tejer con otras organizaciones, NG promueve la perspectiva de un desarrollo local comunitario que sea gestionado desde el adentro del territorio, entendiendo esta noción además como un caminar multidimensional más que en la planimetría y unidimensionalidad que plantea la modernidad desarrollista. Es decir, cuando hablamos de desarrollo cultural y comunitario estamos diciendo que los términos de referencia no están dados por la regla de un progreso bajo la taza de productividad, estaríamos hablando de la promoción de la cultura como factor fundante en el desarrollo comunitario.

Planes alternativos de desarrollo como el que construyen estas organizaciones alcanzan a darse en Medellín particularmente bajo el gobierno municipal del entonces Alcalde Alonso Salazar (2008-2011), quien, de acuerdo con varios líderes organizativos, tuvo una gran apertura hacia el desarrollo local y hacia la inclusión de las organizaciones tanto desde la planeación como desde la distribución de recursos, si se le compara con otros gobiernos.

Recordemos que Alonso Salazar, como escritor e investigador había participado de procesos con organizaciones como la Corporación Región, donde coordinó trabajos vinculados a mejorar la situación de los sectores populares, particularmente frente a la necesidad de ampliar los límites de la lectura sobre el conflicto armado y el narcotráfico en Medellín.

\section{Cultura Viva Comunitaria: sentidos red-tejidos.}

Encontramos que uno de los grandes aportes y saberes acumulados por la Corporación Cultural Nuestra Gente es su capacidad para construir y articular trabajo en red a lo largo de sus 
años. Esta acción de tejer con otros ha permitido fortalecer su trabajo y la comunidad en diversas formas, este Red-Tejer tiene algunas particularidades que discutiremos.

$\mathrm{Al}$ interior del colectivo se evidencia una naturalización del trabajo con otros como algo indispensable para construir un proyecto de trasformación. Esto se vislumbra desde el énfasis puesto en los procesos formativos al desarrollo de lo que NG denomina como "pensamiento colectivo". De igual manera, se evidencia que la postura ético-pedagógica de "formarse con el otro" les ha permitido considerar el trabajo articulado desde las redes como un espacio formativo en sí mismo que alimenta el proceso desde dentro del colectivo, generando un saber que circula intrínsecamente hacia el ejercicio de dialogo con la comunidad barrial. Esto asume un círculo más amplio cuando se articula este saber experiencial a sus trabajos en red; un ejemplo es el Festival de Teatro Joven Comunitario llevado al territorio local y resignificado desde la interacción con la comunidad.

Este red-tejer característico de las acciones de NG no se enuncia en términos de la formación dirigida alrededor de procesos artístico-pedagógicos, sino como la sumatoria de los ciclos y prácticas mencionadas en este capítulo y en su devenir histórico organizativo. Sin embargo, hace parte integral de lo que distingue a NG desde este estudio, razón por la cual se asume esta redtejer bajo la categoría de saber-respirado, entendiéndolo como aquel saber que se vuelve tan imperceptible como la propia respiración pero que es vital en la identidad y desarrollo de una organización. Son saberes que están tan a flor de piel de la organización, que son asumidos en la esencia de la cotidianeidad.

Dentro de las redes de las que participa NG, se destaca el trabajo que actualmente viene realizando desde la Plataforma Puente Cultura Viva Comunitaria donde reaparecen trazos de una articulación latinoamericana que involucra lo sentipensante, una movilización de geografías populares que articula experiencias de vida y comunidad desde la Cultura, un entendimiento que sobrepasa su versión antropocentrista, y una versión antifragmentaria que suma cultura y naturaleza en un resultante denominado Cultura Viva Comunitaria.

Nuestra Gente hace parte de la Plataforma Puente Cultura Viva Comunitaria, esta red cobra vida a raíz de una sucesión de encuentros y trabajo en red a nivel latinoamericano, inicia en el 2009 con el encuentro sobre arte y trasformación social en Mar de Plata, Argentina en el 2009 (En este evento Nuestra Gente socializó su experiencia organizativa comunitaria). Uno de los objetivos centrales de esta red era entender mejor la experiencia que se estaba dando en Brasil con Puntos de Cultura (2004), surgida en el Gobierno de Lula Da Silva desde el Ministerio de la Cultura con Gilberto Gil; su principal arquitecto Celio Turino, quien era el secretario de ciudadanía cultural. Para Gilberto Gil, los Puntos de Cultura se asemejan a los puntos de la acupuntura, un do-in Cultural, un automasaje de estos puntos para activar la cultura propia. De acuerdo con Iara Machado, artista brasileña y miembro de la red de Cultura Viva Comunitaria, "Este proyecto significaba potencializar las culturas que ya existían, unas culturas de pensamiento propio, que fueron borradas y no vistas como culturas que vinieron sobreviviendo desde mucho tiempo" (Entrevista Lara Machado, enero 10 de 2015). 
En el Primer Congreso Latinoamericano de CVC, realizado en mayo de 2013 en la Paz (Bolivia), se consideró que "Según datos del primer congreso latinoamericano, existe en la región más de 120.000 experiencias donde organizaciones sociales y corporaciones culturales promueven la producción y distribución de bienes culturales en sus comunidades, sin intereses lucrativos e inscritas en procesos de democratización y desarrollo local. Son centros culturales, bibliotecas populares, agrupaciones de hip hop, colectivos de muralismo, plástica en general, producción audiovisual, grupos de teatro comunitario, arte callejero, circo, radio comunitaria y otras experiencias de comunicación popular, rescate de prácticas ancestrales y culturales, etc; (...) de carácter barrial y comunal” (Pp. 4-5)

La mirada sobre una Cultura Viva desde los Puntos de Cultura estaba orientada a la constitución de una red orgánica que apoyara la creación cultural, en palabras del propio Celio Turino se trata de:

"Punto de Cultura es un concepto. Un concepto de autonomía y protagonismo sociocultural. En la dimensión del arte, va más allá de la exaltación de un arte ingenuo y simple, como si al pueblo le cupiera solamente el lugar de artesanato y de lo no elaborado de acuerdo con los cánones del buen gusto. Por el contrario, busca sofisticar la mirada, apurar los oídos, oír el silencio y ver lo que no se muestra. (...) Narrativas que establecen un diálogo a partir de la voz de quien hace su propia cultura y no por medio de la voz del "otro" (Turino 2013, Pp.20-21)

La invitación de Celio Turino parte del silencio y la escucha para ver y entender aquello que ha permanecido oculto y deslegitimado. Así mismo, lo que puede generar una política pública pensada como ruptura en términos de la relación que se han mantenido entre el conocimiento y reconocimiento de lo que está vivo en los barrios. Esta es una confluencia que podemos encontrar en el trabajo de NG en su construcción organizativa comunitaria donde el respeto por el otro hace parte de su postura ético-política.

Esta posición se verá reflejada en los procesos formativos, específicamente, en la relación entre formadores y los niños y jóvenes que pasan por el proceso pedagógico en los diferentes programas de Nuestra Gente. Como dice su director actual Jorge Blandón "las metodologías nuestras parten de la escucha", mientras que los puntos de cultura parten de la experiencia cultural construida en los barrios y veredas. NG parte de lo que el niño o el joven trae consigo para potenciar el respeto y la escucha e integrar la afectividad dentro el proceso artísticopedagógico; así su propuesta pedagógica de Artistas para la Vida cobra sentido.

Existe entonces una ruptura en la forma en la que se concibe la cultura y el acto educativo. En ambos casos se presenta la mayor parte del tiempo la visión institucional de cultura, concebida desde los gobiernos, las universidades y la institucionalidad pública, mientras que desde este proceso se conciben otras rutas.

En este propósito de incidir políticamente y reconocer aquello que está vivo en los barrios de Medellín, esta red de organizaciones locales de la cual NG es un componente vital (Convivamos, Corporación Semiesfera, Platohedro, Corporación Simón Bolívar, Corporación Canchimalos 
entre otros), logró materializar en el 2011, una política pública desde el trabajo de la red de Cultura Viva Comunitaria; se hace referencia al Acuerdo 50 "Por medio del cual se establece una política pública para el reconocimiento y la promoción de la cultura viva comunitaria en la ciudad de Medellín" y que se da en medio de la visita de Celio Turino a la ciudad de Medellín. De igual manera, el encuentro de redes en Medellín en el 2010 y la aprobación de esta política pública logran impulsar el movimiento a nivel nacional particularmente en Cali y Bogotá. La firma de este acuerdo municipal sella un compromiso institucional en términos políticos y de recursos públicos, con el fin de potencializar procesos educativos y culturales ya existentes como el de NG que viene actuando como gestor de convivencia en los barrios de Medellín.

Acciones como estas dan cuenta de la incidencia que el trabajo de NG ha logrado configurar tanto desde el compromiso comunitario como desde el red-tejer que se destaca como unos de los saberes que los identifican no solo como punto de Cultura en Medellín sino como punto de articulación comunitario -cultural en Colombia y Latinoamérica, como lo constata el trabajo que viene realizando desde diversas redes.

\section{Conclusiones.}

La construcción de un proyecto cultural desde NG viene claramente vinculado a una propuesta artística-pedagógica. En Medellín, NG hace parte de otras experiencias organizativas de base que le han apostado a la construcción de proyectos que articulen la cultura desde lo educativo y el arte, logrando otras relaciones de afecto y efecto en territorios de alta complejidad social, sin contar necesariamente con la institucionalidad. La presencia y proyección de estos colectivos se ha convertido en un "creer en crear desde lo local".

NG hace una contribución importante con su participación en esta red en términos reivindicativos frente a las experiencias de base y su reconocimiento como focos de desarrollo cultural local que son asumidas desde lo presupuestal en las políticas municipales. Esto evidencia que el trabajo de organizaciones como NG vincula la búsqueda de mejores posibilidades no solo para la comunidad barrial local y de las organizaciones de la zona actuales o futuras, sino que su lucha y fortaleza organizativa trasciende a la ciudad de Medellín. Esta construcción popular comunitaria de tres décadas permite reconocer un tejido desde un legado latinoamericano, muchas veces invisible, que en nuestros territorios ha constituido diversos procesos organizativos y cuyos aportes han permitido enriquecer "lo popular y lo comunitario" como lugares de construcción de otros saberes y subjetividades, prácticas y experiencias localizadas que circulan desde lo local y nuevamente alimentan el red-tejido latinoamericano.

Aunque procesos como el de Cultura Viva Comunitaria demandan un esfuerzo grande de organizaciones como NG que en el día a día buscan financiación para que sus procesos artísticopedagógicos sigan construyendo comunidad, la apuesta de un red-tejer desde NG parece dar frutos más allá de su razón de incidencia local. Desde este tejido cultural comunitario que se extiende por Latinoamérica vale la pena preguntarse: 
¿Qué significaría pensarse no solo puntos de cultura, sino puntos educativos, puntos de convivencia, puntos de semillas y naturaleza para la ciudad de Medellín?

En tal cuestionamiento acudo a las palabras de Jorge Blandón que además de ser una primera réplica a este interrogante, reflejan precisamente lo que ha sido el corazón del red-tejer de NG: "La pregunta necesita del encuentro"; en esta frase aparece una perspectiva ontológica, pedagógica, y epistemológica que habla de la necesidad del ser humano de tejerse con otros para darle sentido a su propia existencia, reconociéndose en el rostro del otro surge también un interés por la vida tejida en colectivo. En la experiencia de NG consideramos que lo pedagógico le ha dado centralidad al proceso de formación como espacio de encuentro, espacio que podemos identificar como circular en la medida en que rompe con la estructura bancaria e individualista de otras pedagogías.

La circulación de la pregunta en la experiencia pedagógica establece una relación libertaria con los sujetos, puesto que la pregunta no surge de un docente que evalúa un educando, sino de varios ciclos que permiten a las subjetividades circular con sus preguntas y respuestas. Finalmente, el sentido de la palabra encuentro, bajo esta mirada epistémica se construye afectivamente con otro. Es decir, este encuentro involucra una postura que trasciende la racionalidad e involucra al cuerpo-territorio como lugar para la construcción colectiva sentipensante que se moviliza en el círculo del conocimiento desde la calidez que le otorga sentido y palpitar.

\section{Bibliografía.}

Bernal M, J. A. (1992). Mecanismos y posibilidades de la participación ciudadana en Medellín. En En Consejería Presidencial para Medellín y el Área Metropolitana. Medellín: Alternativa de Futuro: Presidencia de la República.

Corporación Cultural Nuestra Gente. (2011). Plan sectorial de Cultura de la Comuna 2, Santa Cruz: en una perspectiva transformadora de la Educación. Medellín.

Ghiso, A. M. (2016). Profesionalización de pedagogos sociales en latinoamerica. Otra lectura a los tránsitos entre la educación popular y la pedagogía social. El Agora USB, 16(1), 6375. Obtenido de http:// revistas.usb.edu.co/index.php/Agora/article/view/2165/1893

Insuasty Rodriguez, A., Bastidas, W., Carrion, J., \& Balbin Alvarez, J. W. (2010). Las Victimas en Contextos de Violencia e Impunidad: Caso Medellín. Medellìn: Instituto Popular de Capacitaciòn.

Insuasty Rodriguez, A. (12 de agosto de 2015). Contextos y transformaciones. Kavilando, 7(2), 113-115. http://kavilando.org/revista/index.php/kavilando/article/view/42

Insuasty Rodriguez, A., \& Villa Holguin, E. (2014). Capital, sujeto y ciudad. Lecturas de la ciudad y la crisis humanista. El caso Medellín. El Agora USB, 87-96. 
Montoya, J., Rojas, M., \& Castañeda, V. (2012). Artistas que Construyen Ciudadanía. Medellín: Rocco Gráficas.

Naranjo Giraldo, G. (1992). Medellín en zonas. Medellín: Corporación Región.

Plataforma Puente. (28 de septiembre de 2011). Plataforma Puente, cultura viva comunitaria: un relato. Obtenido de www.plataformapuente.blogspot.com: http://plataformapuente.blogspot.com/search?q=organizaci $\% \mathrm{C} 3 \% \mathrm{~B} 3 \mathrm{n}+$ comunitaria

Quintero, Y., \& Muriel, E. (2014). Memoria Viva: Sistematización Proyecto Memoria Viva de los Barrios de la Comuna 2 Santa Cruz: Medellín: Rocco Graficas.

Rojas, M. (2011). Hacia la construcción del modelo pedagógico de la Corporación Cultural Nuestra Gente (Monografía). Medellín: Universidad de Antioquia - Facultad de Artes.

Salazar J, A. (1993). La criminalidad urbana: Actores visibles e invisibles. Revista Foro, 38-44.

Turino, C. (2013). Puntos de cultura: cultura viva en movimiento. (L. Tennina, Trad.) Caseros: RGC Libros.

Villa Holguín, E. (2011). Politizar la praxis educativa. Hacia la construcción de un Congreso Educativo de los Pueblos. Revista CEPA, 83-90. Obtenido de http://revistacepa.weebly.com/uploads/1/3/3/7/13372958/de_pura_cepa_politizar_1 a_praxis_educativa.pdf

Zemelman Merino, H. (20 de agosto de 2015). Pensamiento y construcción de conocimiento histórico, una exigencia para el hacer futuro. El Agora USB, 15(2), 343-362.

Zibechi, R. (20 de enero de 2014). Liberar el mundo nuevo que late en el corazón de los movimientos. Kavilando, 6(1), 7-14. Obtenido de http://kavilando.org/revista/index.php/kavilando/article/view/71/58

\section{Nota.}

${ }^{i}$ Este artículo hace parte de la investigación "Pedagogías con raíz latinoamericana: Experiencias de formación popular comunitaria con Nuestra Gente" perteneciente al programa de formación doctoral en Estudios Culturales Latinoamericanos de la Universidad Andina Simón Bolívar. El ejercicio de este artículo, así como los diálogos establecidos detrás de los sentidos del texto hacen parte de los resultados de esta investigación y de posteriores reflexiones con integrantes de la organización. 